\title{
Subtitle Translation of American Sitcom The Big Bang Theory From the Perspective of Eco-Translatology
}

\author{
Jing Cao \\ Faculty of Modern Languages and Communication, Universiti Putra Malaysia, Serdang, Malaysia \\ Nor Shahila Binti Mansor \\ Faculty of Modern Languages and Communication, Universiti Putra Malaysia, Serdang, Malaysia \\ Lay Hoon Ang \\ Faculty of Modern Languages and Communication, Universiti Putra Malaysia, Serdang, Malaysia \\ Diana Abu Ujum \\ Faculty of Modern Languages and Communication, Universiti Putra Malaysia, Serdang, Malaysia
}

\begin{abstract}
Eco-translatology is a theory of translation put forward by Professor Hu Genshen, which regards translation as a process of "selective adaptation" and "adaptive selection". The popularity of American TV dramas has aroused a huge demand for subtitle translation, resulting in the rapid growth of subtitle translation by fansub groups and increasing enthusiasm for subtitle translation studies in China. While there is no accordant idea about the understanding of subtitle translation of TV dramas on the internet translated by fansub groups. Based on the theoretical framework of Eco-translatology theory, this study examines the subtitle translation of The Big Bang Theory to analyze translators' "selection" and "adaptation" on linguistic, cultural, and communicative dimensions. It also pays attention to the inappropriate selection of translation techniques made by the fansub groups. The analysis shows that in the translation process of The Big Bang Theory's subtitles, the translators adopted various translation techniques which include the applications of buzzwords, Chinese idioms, annotations, and free translation to implement adaptive selection in linguistic, cultural, and communicative dimensions. And the fansub groups make some inappropriate selections as abusing the Chinese dialect in translation. These findings attempt to provide a reference for subtitle translation of American TV dramas available on the internet, as well as evidence of the explanatory power of Eco-translatology theory in subtitle translation studies, in order to supplement a new perspective on subtitle translation and more attention on this developing translation theory.
\end{abstract}

Index Terms - eco-translatology, three-dimensional transformation, adaptive selection, translation techniques, inappropriate selection

\section{INTRODUCTION}

After the year 2000, the development of the internet in China has made a great contribution to the boom of American TV dramas, particularly Prison Break in 2006, which had a remarkable start and success among Chinese netizens ${ }^{1}$. From 2015 to 2020, the number of American TV series played on Tencent's Video Website alone was 2.45 million to 680 million (Zhong, 2021, p. 65). The popularity of American TV dramas has aroused a huge demand for subtitle translation, which results in rapid growth in this area and increasing enthusiasm for subtitle translation studies about American TV dramas on the internet. However, not many studies in this area are conducted from the perspective of Eco-translatology. It is a theory put forward by Professor Hu Gengshen that can be used to demonstrate how translators of subtitle translation make translation survive through adaptations and selections in a transitional complicated eco-environment.

The Big Bang Theory (hereafter TBBT) is an American sitcom that was first presented on CBS on September $24^{\text {th }}, 2007$. It has been nominated more than 50 times by the Emmy Awards and other TV show authorities. It has been favored by millions of audiences in China and has consistently scored above 9 on the Chinese film and television rating platform, Douban, with a maximum score of 9.6. The appreciation and popularity of it in China owns not only to its featured language with the scientific knowledge, cultural differences, and religious factors, but also to its subtitle translation. The translation of its subtitle is produced by fansub groups on the internet. Thus, its featured language and translation are worth studying.

Many scholars have attempted to analyze the translated subtitles of TBBT produced by fansub groups on the websites

1 “These are the people who as citizens of the Net, I realized were netizens ..."(Hauben, 1997, p3). 
in specific aspects, such as humor representations (Yang, 2017; Del, 2020), discourse analysis (Wang, 2020), and metaphor translations ( $\mathrm{Li}, 2021)$. However, little attention has been paid to the translation techniques and subtitle translation of TBBT as a "selection" process from the perspective of Eco-translatology. As a theory advocated by a Chinese scholar, Eco-translatology arouses little attention in the western academic community. Therefore, there is a large room for practical studies in this area.

This study intends to examine the subtitle translation of The Big Bang Theory to analyze translators' "adaptive selection" in linguistic, cultural, and communicative dimensions under the theoretical framework of Eco-translatology theory. It also pays attention to the inappropriate selection of translation techniques by the fansub groups in the subtitle translation of TBBT. Finally, it proposes a possible reference for subtitle translation of American TV dramas on the internet and offers a new perspective in subtitle translation studies to enrich the theoretical framework in this field. Meanwhile, it can provide proof for the explanatory power of Eco-translatology to subtitle translation and supplement more attention and discussion on this developing translation theory.

\section{OVERVIEW AND LITERATURE REVIEW}

\section{A. The Subtitle Translation in an Era of TV Dramas on the Internet in China}

In 1922, the Shanghai Peacock Film Company pioneered in making foreign films shown with Chinese subtitles (Yu, 2015, p. 498). Subsequently, the subtitle translation in China kept changing due to various factors till the $21^{\text {st }}$ century. By virtue of the application and popularity of the Internet, people are no longer confined to watching limited TV programs, but more actively choose the Internet to watch American TV dramas (Zu, 2020). Because the English language abilities of the audiences are uneven, most Chinese need to understand the plot development of American dramas and western culture through Chinese subtitles. There are many differences between English and Chinese in the ways of expression, customs, and value orientations. When it comes to subtitle translation from English into Chinese, it is the usual case that English subtitles occupy more space than Chinese ones in terms of the utterance length due to their differences in the graphic system and syntactic structures (Yu, 2015).

Huge demands for subtitle translation of TV dramas on the internet have spawned fansub groups in China. Fansub groups are groups of people who translate and add subtitles to foreign films or foreign television programs. Most members of domestic fansub groups are people who love translation or college students with different levels of translation abilities, and the quality of their translations is also uneven (Meng, 2021). Zou and Zhu (2021) hold the idea that the communication form of "transformational translation" created by fansub groups is dispersive, uncorrelated, irrational, and difficult to regulate. However, there is no accordant idea about the understanding of subtitle translation of TV dramas translated by fansub groups.

\section{B. Previous Studies on Subtitle Translation of TBBT}

Lots of previous scholars put their interests in the translation of humor in subtitle translation, taking TBBT as the case. Both Yu (2014) and Lu (2017) conducted studies about the representation of humor in the subtitle of TBBT under the scope of the Relevance Theory. Yu (2014) focused on direct translation and indirect translation, while Lu (2017) talked about it from a self-built framework as language humor, cultural humor, and common humor. Li (2018) categorized the type of humor in the subtitle of TBBT with some translation examples and then explained the translation method.

Some attention has also been paid to the translation strategies for the subtitle translation of TTBT. Li (2016) studied this from the perspective of Relevance Theory, focusing on the linguistic aspects. Therefore, in terms of "direct translation" and "indirect translation", the translator in the said study used conversions, annotations, analogies, and paraphrasing respectively. $\mathrm{Li}$ (2017) studied the principles and strategies of subtitle translation of films and TV dramas, taking TBBT as a case. But based on the principles that it was analyzed, "creative translation strategy" may not be regarded as a translation strategy. Meanwhile, Wang (2019) conducted an analysis that is specific on domestication in the subtitle translation of TBBT.

\section{Eco-translatology: A Translation Theory with Oriental Wisdom}

It has been 20 years since 2001 when Professor Hu Gengshen ${ }^{2}$ published his first paper on Eco-translatology. In these years, from the presentation of various terms to the convening of academic conferences (2010 in Macau; 2012 in Chongqing, and so on), and then to the publication of systematic books (Chinese version in 2013, English version in 2020), Eco-translatology theory has experienced a comprehensive development.

The notion of "Translational eco-environment" firstly appeared in 2001 in Initial Exploration into Translation as Adaptation and Selection by $\mathrm{Hu}$ Gengshen for a conference (2001), referring to "the worlds of the source text and the source and target languages, comprising the linguistic, communicative, cultural and social aspects of translating, as well as the author, the client, and the reader" (Hu Gengshen, 2004, p. 90). According to Hu, the process of translating comprises two stages, including the translational eco-environment that selects the translator and the translator that selects or decides on the form of the final target text (Hu, 2004, p. 222). The translator should make a "selective adaptation" to the

\footnotetext{
${ }^{2} \mathrm{Hu}$ Gengshen is Professor Emeritus at the School of Languages and Translation, Macao Polytechnic Institute, Macao, and at the Department of Foreign Languages and Literatures, Tsinghua University, Beijing. (https://forumtis.gdufs.edu.cn/info/1040/1055.htm)
} 
"translational eco-environment" and then make a "selective adaptation" to produce a translation version.

Eco-translatology has aroused continuous discussion among Chinese domestic scholars. For Meng (2019), it was an excellent translation research discourse system with unique and profound Chinese ecological wisdom and both Chinese and Western academic norms. While affirming the value of Eco-translatology, Wang (2021) thought that Hu Gengshen's "translation as an adaptive choice" was similar to Levy's descriptions of translation that were based on game theory; both of which were based on the idealized assumptions inherent in rational choice theory. Therefore, it had limited descriptive power for some idealized translation phenomena but could not objectively describe the universal translation phenomena in the empirical world (Wang, 2021, p. 90).

\section{THEORETICAL FRAMEWORK}

\section{A. The Origin of Eco-translatology Theory}

To begin with, Eco-translatology emerged along with the trend of international ecological interests which reflected the turn of social civilization in translation to some extent. Since the 1960s, human society's interest has turned from industrial civilization to ecological civilization. In 1972, the Declaration of Human's Environment was published to stress environmental protection. Along with this trend and atmosphere, the concept of "ecology" was widely accepted by many social science researchers and became more and more popular. Moreover, it also started to emerge with the philosophical turn. In the 19th century, the theory of "Deep Ecology" (Naess, 1973) introduced ecology into the field of philosophy and ethics, laying a solid foundation for the development of Eco-translatology.

Furthermore, eco-translatology has deep roots in philosophical ideas and specific backgrounds, as many Chinese cultures embody ecological consciousness, such as "the philosophy of moderation," "the Dao follows nature," and "people-oriented" (Meng, 2019).

Moreover, eco-translatology arose from translation studies as perceived by ecology. It was true that there was much research on translation in light of "environment", "ecology", "survival", "adaptation" and "selection" before Eco-translatology came into being. For instance, Nord (1994) regards translation as a process of cultural and linguistic adaptation and Kantan (2004) once classified the ecological culture of translation.

\section{B. Main Concepts of Eco-translatology Used in This Research}

\section{Translation Process: Adaptation and Selection}

Guided by Darwin's “adaptation and selection” theory, Hu Gengshen defines translation as a selection of activities by a translator so as to adapt and fit into the eco-environment of the translating work (Hu, 2003). According to Eco-translatology, the process of translating comprises two stages, including the translational eco-environment that selects the translator and the translator (who stands for the translational eco-environment) that selects or decides on the form of the final target text $(\mathrm{Hu}, 2004)$. That is to say, the translator should conduct "selective adaptation" to the translational eco-environment and "adaptive selection" to select the most effective and proper translation strategies.

\section{Three-dimensional Transformation: Linguistic, Cultural and Communicative}

In Eco-translatology, the translator must make various selections based on adaptations to the translational eco-environment, which could be summed up as "multi-dimensional adaptation and adaptive selection" (Hu, 2004). Subsequently, "multi-dimensional adaptation and adaptive selection" can be centralized in a three-dimensional transformation including linguistic, cultural, and communicative dimensions.

Linguistic transformation: the translator must select suitable and adaptive transformation in different levels in the light of linguistic forms, such as the adoption of semantic meaning, phonetic selections, vocabulary and sentence arrangements, and so on.

Cultural transformation: the successful transmission of cultural connotations is a significant standard for judgment of a translation. A translation that ignores cultural connotations and background could hardly arouse the readers' interests and reorganization.

Communicative transformation: emphasis should be put on the communicative level, which is the realization of communicative purposes. Without communicative effects, information is useless. The translator should deliver clear information and convey the true communicative intention to the readers or audiences.

However, it has to be declared that there are some other adaptive selections besides the above three-dimensional transformation like marketing, goals, and timing that should be considered when choosing a suitable translation strategy according to Eco-translatology. Therefore, the translator should not only confine himself to the three-dimensional transformation but should also take other factors into consideration.

\section{METHOD}

This paper presents a qualitative study of English subtitle translations of TBBT. The study employs the descriptive qualitative approach. Descriptive translation studies "describe the phenomenon of translating and translation(s) as they manifest themselves in the world of our experience" (Holmes, 1988, p. 71).

The data of the current study consists of two versions of subtitles of the first ten seasons of TBBT; the first set of data is 
the subtitles in the source language, Chinese, and another set of data is translated subtitles in the target text, English. The data was gathered from the YYe Ts (Videos Website) since its fansub group has been the longest developing and largest one in China (Wang, 2020).

The transcription process followed the standard procedures that involved an overall observation on the computer screen to understand the story of each episode, and this process was then repeated for a second observation. All the dialogues or interactions in English and the translation in Chinese contained the factors and challenges in the translation process related to linguistics, culture, and communication were paid extra attention and 10 of them were selected for data analysis. Meanwhile, the inappropriate translations which set up the obstacles to understanding were also paid attention to and two of them were demonstrated as examples.

The process of analyzing the data for this study was conducted according to Eco-translatology, based on its framework of three-dimensional transformation on linguistic, cultural, and communicative dimensions. To make the analysis understandable to other language readers, literal translation is provided to all the target text examples in Chinese language.

\section{FINDINGS AND DisCUSSION}

\section{A. Three Dimensional Transformation in the Process of Adaptive Selections}

\section{Linguistic Dimension}

For the linguistic dimensional transformation, the translators mainly focus on two aspects: lexical level and syntactic level, using different translation techniques as follows:

\section{a. Application of Buzzwords}

Buzzwords can be seen as a form of popular language on the Internet, as well as the conventional expressions used by netizens, which are brief and strong in summary, often creating a humorous atmosphere. Buzzwords come from the necessity of substituting the limited ability of modern Chinese in network communication with the more dynamic ability of modern Chinese. People use the inherent rhetoric in Chinese creatively, which has greatly enriched the connotations of modern Chinese. In the following translation examples, the translator applied buzzwords to make the translation more abundant.

Example 1:

Rajesh: OK, first order of physics bowl business. We need a truly kick-ass team name.

Translation:

Rajesh: 我们需要一个很拉风的队名。

Literal translation: We need a very cool name.

(TBBT: S01E13)

Example 2:

Howard: Ok, simulated zero-gravity human waste disposed test.

Sheldon: Fascinating!

Translation:

Howard: 好, 模拟零重力环境人类排泄物处理测试。

Sheldon: 很好很强大!

Literal translation: Very good and very powerful.

(TBBT: S02E22)

In example 1, "kick-ass" is intended to be "strong, brutal". In this setting, the audiences can get a clue that what Rajesh needs is a quiet rock and a great name. The translators translate it as the popular words “拉风” (which means "super cool"), strengthening the sense of the sitcom. According to Yu (2010), buzzwords are not only a linguistic phenomenon but also a cultural and psychological phenomenon that is a mirror of the time, a reflection of the social change, cultural life, and mass psychology of a specific historical period. In example 2, a single word in the source text is translated into a phrase in the target text. The popular sentence structure “很......很......" (which means "very...very”) is a transformed quotation of “很俊很天真” (means “very silly and very naive”) coming from the sex scandal of a Chinese superstar in 2008. For quite a long time, people made up many similar structures like "very...very" to express humor or sarcasm. Here, the result of Howard's text was a very funny failure mocked by others. The application of buzzwords successfully gains humor and derision more locally and understandably for the target audiences.

\section{b. Applications of Chinese Idioms}

English is a kind of language that focuses on hypotaxis, while Chinese stresses on parataxis. Hypotaxis refers to the realization of word or phrase connections with the help of language forms (including vocabulary and forms). Parataxis, on the other hand, describes the realization of word and phrase connections without the aid of language form, but rather the logical meaning of the words or phrases. To the target audiences, the formative sentences with long and sometimes loose structures are not easy to understand. Additionally, some Chinese idioms have similar meanings and are quite acceptable, which may have better effects in translation. The translators make the translation more colorful through the application of 
Chinese idioms as follows:

Example 3:

Howard: That was absolutely humiliating.

Leonard: Come on, some battles you win, some battles you lose.

Translation:

Howard: 真是太丢人了。

Leonard: 好了, 胜败乃兵家常事嘛。

Literal translation: It is very common for the army to win or lose.

(TBBT: S01E06)

Example 4:

Penny: What happened?

Leonard: Nothing. Mother likes looking at brains and Sheldon likes getting his brain scanned.

Penny: Geez, what a fun couple.

Translation:

Penny: 怎么了?

Leonard: 没事, 老妈喜欢扫描人的大脑, Sheldon 喜欢被人扫描大脑。

Penny: 一个愿打, 一个愿挨。

Literal translation: One is willing to beat the other, and the other one is willing to be beaten.

(TBBT: S02E15)

In example 3, "Some battles you win, some battles you lose" is a typical English inverted sentence, neat and antithesis. Literal translation can just convey the meaning but will lose the charm of the rhetoric of the original language. The translators borrow the idiom with the meaning that it is common to lose or win in battles, which is very refined and conveys the exact information, enabling the translation to become more authentic at the same time. In example 4, "what a fun couple" shows Penny's plaint at the remarkable understanding between Sheldon and Leonard's mother. They both could accept the ideas of each other, which was considered crazy in others' eyes.

\section{c. Annotations}

In some circumstances, some words may have the same pronunciation but different spelling, and the scriptwriter may deliberately use the words with two meanings like a pun to create humor or irony. Since the target audiences have limited knowledge of English and translation, simple words are not adequate for them to fully understand what is going on. The translators use annotations to add to the implied meaning of the words and illustrate the original purposes of the scriptwriter.

Example 5:

Sheldon: Perhaps he's at a sensitive point in his monthly cycle.

Howard: Are you saying he's man-struating?

Translation:

Sheldon: 也许他正处在每个月的敏感期。

Howard: 你是说他大姨夫来了（与 menstruating 同音）?

Literal translation: Are you saying that his Big Aunt's husband is coming (same pronunciation with menstruating)?

Example 6:

(TBBT: S03E19)

Leonard: What would you be if you were attached to another object by an inclined plane wrapped helically around an axis?

Sheldon: Screwed.

Translation:

Leonard: 如果你被绑在一个围绕轴心成螺旋状的斜平面上的话 你的下场会是怎样?

Sheldon: 拧一块儿了（也有完蛋了的意思）。

Literal translation: Twisted together (also means "screwed up").

(TBBT: S04E05)

In example 5, "man-struating" is the keyword. It was made by Howard to jibe with Leonard. It was because Leonard had the regular monthly sensitive performance like a girl, according to Sheldon's description. Howard made this word based on the word “menstruating”. For Chinese, “大姨妈” (Big Aunt) is a metaphor for girls' menstruation. And then “大姨夫” (husband of the Big Aunt) is a fun way to tease a man about having menstrual problems. If the translator does not give the annotation, the whole soul of the humor that lies in this sentence will be lost. More importantly, the intention to use buzzwords to make it more enjoyable cannot be realized. As in example 6, the original text played a pun trick. Sheldon consulted Leonard about the issue with Amy because Leonard didn't have a clue about the relationship and was rather scared about meeting Amy's parents. Leonard tried to use the physical phenomenon to explain it to Sheldon because it was easier for him to understand. The word "screwed" can refer to the result of the physical phenomenon and can indicate the consequences of Sheldon that Leonard tried to describe. To let the target audiences understand and laugh, 
using annotations is the best way.

\section{Cultural Dimension}

Cultural differences have always made translation very challenging. TTBT enjoys not only typical American culture, Indian culture but also some Indian and Jewish religious factors. The following examples can show how the translators used annotations and free translation to achieve adaptive selections and transformations in the cultural dimension.

Example 7:

Rajesh: I'm sorry. Where's the tumbleweed? Where's the saloons? This does not look like Texas.

Translation:

Rajesh: 等等, 风浪草呢? 小酒馆呢? 这一点都不像德克萨斯（老电影中的德克萨斯州的常见的景象）。

(Literal translation: Hold on. Where's the tumbleweed? Where's the saloons? This does not look like Texas. (A familiar sight of Texas in old movies)

Example 8:

(TBBT: S03E01)

Rajesh: It's about to tell my parents that I'm not riding an elephant down the

aisle with Lalita Gupta.

Translation:

Rajesh: 我要告诉我的父母, 我是绝不会跟拉丽塔·古塔结婚的。

Literal translation: I am going to tell my parents that I will never get married with Gupta.

(TBBT: S01E03)

In example 7, Rajesh mentioned two images, "tumbleweed" and "saloon", and a place that is Texas. What is the connection between them? There is a huge blank of cultural background which leads to an obstacle in mutual understanding between the source of text and the target audiences. The translators add an extra explanation as "tumbleweed" and "salcon" appear quite often in old movies related to Texas. In this way, the audiences can understand with enough information. In example 8, the translators use the free translation approach to reach the conversion, translating "riding an elephant down the aisle" as "get married".

\section{Communicative Dimension}

In general, communication barriers would mainly occur in the following two situations: Firstly, apart from the literal meaning, the character wants to express another level of meaning which can achieve communicative purposes such as warning and sarcasm. Secondly, sometimes the dialogue is quite long and most obscure to understand with cultural connotations. The translators should simplify the original language, making it clear and concise, and then achieve the purposes of the communication. During the conversion in the communicative dimension, the translators chose the free translation approach as follows:

Example 9:

Leonard: Come on, you can leave if you want, but I'm gonna see it through.

(The guys are leaving)

Leonard: I guess, technically, that was my fault.

Translation:

Leonard: 好吧, 如果你们想走就走吧, 我要坚持到底。 (大家都准备离开)

Leonard: 其实本来就不该带你们来。

Literal translation: I shouldn't have brought you here.

(TBBT: S02E13)

Example 10:

Sheldon: He didn't respond my e-mails, his phone number is unlisted. Tell me what my other option was.

Leonard: You could have waited until morning.... I know, look who I'm talking to.

Translation:

Sheldon: 他没回我邮件, 我又不知道他的电话, 那我还能怎么办。

Leonard: 你可以等到早上啊。….对, 对于你是不可能的。

Literal translation: You could have waited until morning.....oh, right, it's impossible for you.

(TBBT: S02E23)

In example 9, Leonard said that it was his fault but did not display what his fault was. If the translators translate it directly through a literal approach, it will not be very clear to the target audiences and will be inefficient for communication. The subtext of Leonard was that it was his fault for bringing the other four people there in the first place. Thus, the translators offer the entire meaning and tell the target audiences what is going on with the free translation. These adaptive selections help to reach functional communication.

In example 10, Sheldon was in urgent need of meeting Mr. President of the school, but he could not find him anyway. Therefore, he directly went to Mr. President's house at 3 a.m., which was crazy. The original text means “看, 我在跟谁谈 话”. But it seems to be meaningless if it is translated literally. He was talking to Sheldon, and there was no need to ask 
whom he was talking to. Hence, we believe that Leonard has other meanings. Leonard knows Sheldon very well and this is Sheldon who is quirky in his eyes and all his crazy behavior is understandable and predictable in Leonard's eyes. According to these above factors, the translators dig out Leonard's purposes and adopt the free translation approach to translating the meaning as "yes, it's impossible for you".

\section{B. Inappropriate Selection}

Dialect can be seen as the type of language that circulates in particular groups and has distinct regional characteristics. There are many dialect regions in China. The audiences of the region may have a common feeling without obstacles to understanding the translated subtitle with the dialect of the region where they come from. However, certain dialects are not universal, and they can cause dyslexia for people from other areas. There are some Chinese dialect words found in the subtitle translation of TBBT. But these uses of Chinese dialects are inappropriate, which can be seen as deficiencies.

Example 11:

Sheldon: But the truth is, Amy is just as challenging.

Penny: Just as challenging.

Penny: As you.

Translation:

Sheldon: 但事实上, 艾米也一样龟毛。

Literal translation: But the truth is, Amy is just as Gui Mao as you.

Penny: 一样龟毛。

Penny: 跟你一样。

Example 12:

(TBBT: S10E05)

Amy: I can't believe I ditched work for Disneyland.

Bernadette: What did you tell your boss?

Amy: Oh, I was very clever, I did it in stages.

Translation:

Amy: 真不敢相信, 我居然尧班去迪士尼。

Bernadette: 你怎么跟老板说的。

Amy: 我相当聪明, 一步一步铺好哏。

Literal translation: I was very clever. One step by one step Pu Gen.

(TBBT: S06E18)

In example 11, after Sheldon had a disagreement with Amy, people accused him of being difficult to live with. “龟毛” (Gui Mao) is a dialect of Minnan, Fujian province, China which has no common sense at all to people who speak Mandarin. It has three meanings. One is that someone's behavior is different from that of ordinary people, and it makes other people crazy; the second refers to that someone flinches from doing something; the third one means that somebody is particular in something. Even though it has something like the word "challenging" in this context, there will be a huge obstacle in understanding for most of the audiences. Furthermore, “龟毛” (Gui Mao) sometimes is used as a dirty word. Considering Sheldon is a rigid but famous scientist, it is out of his habit to use the word. This abuse of Chinese in Minnan dialect shows that the translators neglect the factor of the character's personality when doing the translation. Therefore, it is improper to use the dialect “龟毛” (Gui Mao) to translate the standard word "challenging”.

In example 12, the context of the dialogue is easy to understand, and it is not necessary to use any dialect in the translation. In addition, “哏” (Gen) is a dialect in Tianjin, which means something is funny, and “铺哏” (Pu Gen) is only used in traditional cross talk, which means "to pave the way for the laughing point". The use of this dialect is an irrational choice.

\section{Discussion}

The analysis shows that the translators have adopted various translation techniques which include the applications of buzzwords, Chinese idioms, annotations, and free translation to implement "adaptive selection" in the linguistic, cultural, and communicative dimensions, resulting in the translation versions that can be seen as successful. In order to achieve a high quality of translation, the translators have paid lots of attention to linguistic, cultural, and communicative distentions and selected the optimal translation techniques.

Used in the translation process, buzzwords can take advantage of their enhanced expressions, resulting in the transmission of the information, and, at the same time, can achieve a certain sense of humor and approachability. However, in translation, a translator should also pay attention to the use of buzzwords in an effort to reach a balance so as not to go overboard.

It also finds that there are some inappropriate selections of translation techniques made by the fansub groups as the abuse of Chinese dialects can be identified in the subtitle translation of TBBT. The abuse of Chinese dialects can set up obstacles for audiences who do not know the dialects in understanding the translation. Unless the plot requires the application of the dialects to achieve certain effects, we should use the dialects carefully in the translation. 


\section{CONCLUSION}

This study presents an analysis of the American sitcom The Big Bang Theory from the perspective of Eco-translatology. To make translation more accurate and efficient, translators select various and flexible approaches to make the translation more adaptable. In the translation process of The Big Bang Theory's subtitles, the translation techniques such as the applications of buzzwords, Chinese idioms, annotations, and free translation are adopted based on the three-dimensional transformation. Through adaptive selections, most of the translated versions successfully overcome language barriers, bridge cultural differences, and help the target audiences to appreciate the sitcom better. However, there is indeed some inappropriate selection made by the fansub groups shown in this study. The abuse of Chinese dialects fails to make the translation version meet the aim of bridging the language barrier. From the discussion above, we can see that Eco-translatology enjoys a high degree of explanatory power in subtitle translation.

In terms of limitation, this study does not talk about the translator's adaptation to the "eco-environment" and the examples are selected under the framework of "three dimensions" as planned. Although there are many limitations in this paper, it is still hoped that the present research can offer a reference for subtitle translation of American TV dramas on the internet and supplement a new perspective on subtitle translation studies. Moreover, more attention and valuable studies on Eco-translatology are expected to explore its further development.

\section{REFERENCES}

[1] Del, M. O. P. M. (2020). The translation of specialized terms with humorous effect in audiovisual texts: The scientific jokes in The Big Bang Theory. Trans, 24, 71-89.

[2] Holmes, J. S. (1988). The name and nature of translation studies. In J. S. Holmes (Ed.), Translated! Papers on literary translation and translation studies (pp. 67-80). Amsterdam: Rodopi.

[3] Hu, G. S. (2003). Translation as adaptation and selection. Perspectives: Studies in Translatology, 11, 283-291.

[4] Hu, G. S. (2004). An approach to translation as adaptation and selection. Hubei Education Press.

[5] Hu, G. S. (2004). Philosophical basis for the theory of adaptation and selection in translation, Shanghai Science and Technology Translation, 4, 1-4.

[6] Hauben, M. (1997). The net and netizens: The impact the net has on people's Lives. In Netizens: On the History and Impact of Usenet and the Internet. Michael Hauben \& Ronda Hauben. Los Alamitos, IEEE Computer Society Press.

[7] Kantan, D. (2004). Translating cultures. An introduction for translators, interpreters and mediators. St. Jerome Publishing.

[8] Li, H. (2017). Research on the principles and strategies of subtitle translation of film and TV series: A case study of the American sitcom The Big Bang Theory. Journal of Yantai Vocational College, 23, 64-66.

[9] Lu, Y. (2017). The translation of humor Language under the guidance of relevance theory: A case study of subtitle translation of The Big Bang Theory. Modern Communication, 4, 97-99.

[10] Li, X. Y. (2021). A study on metaphor translation of American TV drama' subtitle from the perspective of relevance theory: A case study of The Big Bang Theory. Ancient and Modern Literature, 32, 100-101.

[11] Li, Z. N. (2018). A study on subtitle translation of humor in American drama: Taking The Big Bang Theory as an example. Modern Salt and Chemical Industry, 4, 161-162.

[12] Meng, F. J. (2019). On the academic orientation of eco-translatology in Chinese and western translation studies. Chinese Translations Journal, 4, 42-49.

[13] Li, W. X. (2016). On strategies of subtitle translation from the perspective of relevance theory-A case study of The Big Bang Theory [Unpublished master's thesis]. Soochow University.

[14] Meng, J. (2021). Analysis on pragmatic failure in English- Chinese subtitle translation-Taking online American drama Game of Thrones as an example. Journal of Qiqihar Teachers College, 3, 64-66.

[15] Naess. (1973). The shallow and the deep, long-range ecology movement. Inquiry, 16, 95-100.

[16] Nord, C. (1994). Translation as a process of linguistic and cultural adaptation. Teaching translation and interpreting, $2,59-67$.

[17] Wang, D. X, (2020). The impact of China's nonprofit fan-subtitle group on internal culture [Unpublished master's thesis]. Jilin University.

[18] Wang, J. (2021). An analysis of the problems of eco-translatology from the perspective of "pure" translation studies. Journal of Foreign languages, 44(4), 85-93.

[19] Wang, K. X. (2019). An analysis of domestication translation strategies in American TV series The Big Bang Theory. Overseas English, 5, 166-167.

[20] Wang, X. Y. (2020). Subtitle translation of The Big Bang Theory from the perspective of multi-modal discourse analysis. Journal of Guangxi Normal University for Nationalities, 37(4), 97-99.

[21] Yang, L. S. (2017). Analysis of humorous subtitles in American sitcom The Big Bang Theory: From the perspective of skopos theory. Journal of Zhangzhou Institute of Technology, 19(4), p. 58-63.

[22] Yu, H. K. (2015). Film translation in China: Features and technical constraints of dubbing and subtitling English into Chinese. Babel, 61(4), 493-510.

[23] Yu, N. S. (2014). The study of humor utterance translation in The Big Bang Theory from the perspective of relevance theory. Overseas English, 23, 168-170.

[24] Yu, Y. Y. (2010). Translation strategies of Chinese popular words. China Science and Technology Translation, 4, 10-12.

[25] Zhong, K. L. (2021). Audience analysis of American TV series on Chinese online audiovisual platforms. Journal of News Research, 12(10), 65-67.

[26] Zou, C. Y., \& Zhu, X. J. (2021). "Transformational translation" in network translation communication: The perspective of youth's network subculture. Shanghai Journal of Translators, 3, 34-38.

[27] Zu, Y. (2020). A comparative study of Chinese and American audience interpretations in American dramas [Unpublished 
master's thesis]. Jilin University.

Jing Cao, MA, was born in Gansu, China in 1987. She received her Master's Degree in the Department of English Language and Literature from North Normal University in 2014.

She is currently a Phd student in the Faculty of Modern Languages and Communication, Universiti Putra Malaysia. Her research focus is on Translation Practice and Theory.

ORCID ID: 0000-0002-5719-8578

Nor Shahila Mansor, Phd, obtained her Doctoral Degree from the University of Valladolid, Spain.

She is currently a senior lecturer in the Faculty of Modern Languages and Communication, Universiti Putra Malaysia. She has published articles in research journals in the area of her studies. Her research interests include (but not limited to) sociolinguistics, Spanish language and translation.

ORCID ID: 0000-0002-6744-0065

Lay Hoon Ang, Phd, obtained her Master's Degree from Universiti Malaya and a Doctoral Degree from Xiame University, China. She is currently an associated professor of the Faculty of Modern Languages and Communication, Universiti Putra Malaysia. Her research interests are translation, sociolinguistics, Chinese studies and cross-cultural studies.

ORCID ID: 0000-0002-2489-7620

Diana Abu Ujum, Phd, obtained her Doctoral Degree from Universiti Putra Malaysia.

She is currently a senior lecturer in the Faculty of Modern Languages and Communication, Universiti Putra Malaysia. Her research areas are Postfeminist Fiction, Young Adult Fiction, Contemporary Fiction and Popular Fiction.

ORCID ID: 0000-0002-6080-7565 